\title{
Política democrática y cosmopolitismo en el pensamiento último de Julio De Zan
}

\author{
Democratic politics and cosmopolitanism in the \\ last thought of Julio De Zan
}

\begin{abstract}
Jorge R. De Miguel*
Resumen: El artículo trata acerca de la contribución del pensamiento último de Julio De Zan a la filosofía de la democracia y el cosmopolitismo. Las perspectivas abordadas se refieren al rol de la sociedad civil, a la legitimación del poder político y al cosmopolitismo democrático. Todas ellas son interpretadas en torno a la concepción de la sociedad civil contemporánea como el espacio público de construcción del poder democrático. Se destaca la defensa de De Zan de un orden político global no centrado en el Estado tradicional y sustentado en el progreso hacia una comunidad ética de tipo kantiano, como así también su vigorosa invocación de la soberanía como idea desustancializada.
\end{abstract}

Palabras clave: Filosofía política contemporánea, democracia, cosmopolitismo, sociedad civil.

Abstract: The article deals with Julio De Zan's last thought about philosophy of democracy and cosmopolitanism. Different visions such as the role of civil society, the legitimacy of political power, and democratic cosmopolitanism are considered with reference to contemporary civil society as the public space in which democratic power is built. De Zan's ideas of a global political order not organized as a traditional

${ }^{*}$ Doctor en Filosofía (UCSF, 2009), Diploma Superior en Ciencias Sociales, con Mención en Ciencia Política (FLACSO, 1991), Licenciado en Relaciones Internacionales (UNR, 1982), Licenciado en Ciencia Política (UNR, 1976). Actualmente se desempeña como Profesor Titular (UNR y UNL), e Investigador Independiente del Consejo de Investigaciones de la UNR. Autor, entre otros trabajos, de Visiones filosóficas de la democracia (Rosario, AADIE, 2000). Miembro de la Fundación ICALA, de la Red Internacional de Ética del Discurso y del Comité de Ética de la Investigación de la UNR. Dirección electrónica: irdemiguel51@gmail.com 
state and supported in a Kantian ethical community receive a positive comment, along with his powerful invocation of a not substatialized sovereignty.

Keywords: Contemporary Political Philosophy, democracy, cosmopolitanism, civil society.

Este rastreo del pensamiento de tan respetado y admirado colega, con acento en los últimos años de su producción fillosófica, tiene el sentido de un homenaje personal, el cual discurre a través de la exposición y discusión de su legado teórico a la temática de la democracia y su proyección cosmopolita. Era éste, sin duda, un núcleo recurrente de sus preocupaciones como teórico y como ciudadano comprometido con la vida democrática, pero, además, el campo de interés que nos unía y que permitía que mis reflexiones se alimentaran de su razonamiento maduro y de la pasión que lo traspasaba.

\section{Democracia, Estado nacional y sociedad civil}

Tres cuestiones esenciales caben ser resaltadas en la teoría de la democracia que surge del pensamiento último de Julio De Zan: 1) El rol de la sociedad civil y su autonomía respecto del Estado. 2) La legitimación democrática del poder político. 3) El cosmopolitismo democrático como actualización de la idea kantiana de una comunidad global pacífica.

A mi entender, todas estas perspectivas están conectadas por su concepción de la sociedad civil contemporánea como espacio público de construcción de poder político democrático.

Es en el artículo de 2006 sobre ciudadanía y sociedad civil donde puede encontrarse su visión más elaborada de la sociedad civil contemporánea. ${ }^{1}$ Contrastando las doctrinas tradicionales con las teorías filosóficas y sociológicas más recientes acerca de los nuevos sujetos políticos de la sociedad civil, De Zan enlazaba las nociones de ciudadanía y ámbito público de Arendt y Habermas. Respecto de Arendt, rescataba su visión de que la ciudadanía se define por el aparecer en el espacio público mediante el uso de

${ }^{1}$ De Zan, Julio, "Ciudadanía y sociedad civil. La democracia y los sujetos de la política”, Erasmus. Revista para el diálogo intercultural, VIII, 2 (2006), pp. 119-163. 
la palabra. Efectivamente, para la filósofa alemana, el discurso público y la acción conjunta de los ciudadanos originan lo político, así como la reunión en la plaza pública para tratar los asuntos comunes dio lugar a las ciudades antiguas. De ese modo, al transformarse en la preocupación de todos, las cuestiones de la polis dejaron de pertenecer al ámbito privado del monarca. En las sociedades democráticas actuales, subrayaba De Zan, siguiendo a Habermas, lo público no puede entenderse como propiedad de ninguna institución u organización formal, sino que se caracteriza por ser una red de circulación de opiniones, abierta y con horizontes móviles, no exenta de conflictos. Aplicaba así la noción habermasiana del "espacio de la opinión pública", "como una red para la comunicación de contenidos y tomas de postura, de opiniones", que, al igual que el mundo de la vida en totalidad, "se reproduce a través de la acción comunicativa". ${ }^{2}$

Lo propio de lo público, entonces, es el ser visible, el aparecer y el desocultarse. De modo que lo que permanece oculto en la privacidad de los individuos, grupos u organizaciones, carece de entidad política, aunque influya sobre el espacio público. En consecuencia, para De Zan, tal como hoy se la entiende, la sociedad civil no constituye un ámbito privado que se enfrenta al Estado, el cual representaría lo público. En cambio, en la teoría política moderna tradicional, la institución del orden jurídico-político por el contrato o el pacto social transforma, al mismo tiempo, a los contratantes en ciudadanos. Así, lo público queda identificado con el orden estatal (el Leviatán, la sociedad política), al tiempo que la sociedad civil es considerada como pre-política o privada. ${ }^{3}$

2 Ibidem, pp. 119-21. Cfr. Arendt, Hannah, “¿Qué es la libertad?”, en Entre el pasado y el futuro. Ocho ejercicios sobre la reflexión política, trad. A. Poljak, Barcelona, Península, 1996, pp. 157-58; ¿Qué es política?, trad. R. Sala Carbó, Barcelona, Paidós, 1997, p. 46 y ss.; Habermas, Jürgen, Facticidady valider: Sobre el derecho y el Estado democrático de derecho en términos de teoría del discurso, trad. M. Jiménez Redondo, Madrid, Trotta, 1998, p. 440. ${ }^{3}$ En Libertad, poder y discurso (1993), acorde con una discusión corriente por esos años, De Zan planteaba, en cambio, los problemas de la diferencia entre lo privado y lo público. Por un lado, defendía el mantenimiento de la misma y la independencia de la sociedad como condición necesaria para el dinamismo de la vida pública y para la existencia de la libertad personal. Pero, por otro lado, afirmaba que el extrañamiento mutuo de ambas esferas conlleva la no participación ciudadana en lo político, con los 
Es destacable, a mi juicio, que De Zan conecte la reconfiguración de lo público en la filosofía política contemporánea con el abandono de la representación de un macro sujeto unitario, las totalidades colectivas homogéneas de la tradición moderna, como la "voluntad general", una persona pública con conciencia y voluntad común, el "pueblo", la "nación" o el "proletariado" como clase social universal. Tales entidades, aunque explicativas de los avatares que atravesó la conformación de la sociedad moderna, resultan hoy incompatibles con una vida democrática pluralista. En lugar de ellas, nos advertía De Zan, la perspectiva contemporánea de la sociedad civil utiliza otras categorías más abiertas, dinámicas y flexibles, como los "espacios públicos" constitutivos del mundo social: comunidades y asociaciones diversas, exteriores al sistema jurídico-político del Estado y al sistema económico del mercado. Dichos sujetos sociales, unidos por el valor de la autonomía y el pluralismo, se rigen por sus principios e intereses, y no se proponen acceder al poder estatal ni acumular capital. Es así que individuos, familias, movimientos sociales, ONG, comunidades culturales, científicas, religiosas, entre otras, se erigen en un "tercer dominio intermedio", un campo transversal a la distinción público-privado. Por esa razón, tales agrupaciones de la sociedad civil contemporánea, aunque se orienten por intereses particulares, no son meramente privadas, separadas del espacio público. Son "espacios liberados" de los sistemas económico del mercado y político estatal, que impiden el cierre totalitario del Estado, pues mantienen con éste relaciones de oposición y cooperación, siendo un poder comunicativo político relevante en las sociedades democráticas: "el significado común que los une en su diferencia es el valor de la autonomía social $y$ del pluralismo que todos ellos ponen en acción. En estos espacios se construyen los sujetos sociales, en la medida en que las prácticas se tejen mediante el entendimiento intersubjetivo". 4

En consecuencia, a la hora de comprender las sociedades complejas contemporáneas, De Zan se adscribía a la tendencia en la filosofía política

riesgos de "la extinción de la vida democrática y la burocratización del Estado". (De Zan, Julio, Libertad, poder y discurso, Buenos Aires/Rosario, Almagesto/Ross, 1993, pp. 84-85).

4 De Zan, Julio, "Ciudadanía y sociedad civil. La democracia y los sujetos de la política”, pp. 121-22 y 127. Cursivas del autor. 
actual a abandonar la dicotomía moderna Estado-sociedad civil y a reconocer la autonomía de los espacios públicos de la sociedad civil. En particular, suscribía la perspectiva habermasiana de la misma como el entorno en el que funcionan los sistemas mencionados, pero que se mantiene ajeno a ellos, pues no se rige por una racionalidad estatal, ni constituye por sí misma un sistema. Ello queda patentizado en que, más allá de la participación periódica en elecciones, la ciudadanía se manifiesta en debates y acciones que conforman una opinión pública crítica, canalizada por vías distintas a las de la democracia representativa. En este sentido, la teoría de la democracia deliberativa sería aquella que ofrece las categorías más aptas para captar la autonomía y el pluralismo de la sociedad civil contemporánea, mientras que libertarios y comunitaristas permanecen aún en la dicotomía tradicional. ${ }^{5}$

Aplicando todo ello a la experiencia política latinoamericana, De Zan creía que, en nuestro continente, el Estado "ha impedido el buen funcionamiento del sistema económico y la sociedad civil". Por ejemplo, en Argentina, a su juicio, el problema fundamental no está en el sistema económico, ni proviene de raíces culturales o morales, sino que es "el Estado y sus políticas". Muchas constituciones latinoamericanas, imbuidas de una ideología liberal, no han promovido la participación ciudadana y han reducido su ejercicio al acto eleccionario. A su vez, las ideologías antiliberales, populistas o estatistas, con sus tendencias hegemónicas, han sido obstáculos para la formación de una sociedad civil autónoma y diferenciada. ${ }^{6}$

Aún a costa de cierta simplificación, debe decirse que su enfoque rendía cuenta de algunas causas profundas de nuestra decadencia económico-social, en particular, cuando afirmaba que "los procedimientos formales de la generación de la voluntad política reproducen más de lo mismo". ${ }^{7}$ Es por ello que advertía que las estrategias para la democratización política y la lucha por

\footnotetext{
5 Ibidem, pp. 134-35.

${ }^{6}$ Ibidem, pp. 136-37.

7 “Creo que deberíamos preguntarnos, sostenía De Zan, si el funcionamiento del sistema jurídico y político no ha sido constitutiva y estructuralmente funcional al sistema de la injusticia, de la exclusión, del atraso y del subdesarrollo social y económico de América Latina. La sociedad ve de hecho, en gran medida, a la política y al Estado como la causa, o como una parte sustancial de sus problemas, y no como las herramientas de su posible solución" (Ibidem, p. 136.)
} 
una sociedad más justa debían ser pensadas "a partir de la acción de los nuevos sujetos políticos de la sociedad civil, por fuera de los sistemas del Estado y del Mercado", y, a veces, contra estos sistemas. ${ }^{8}$

El descentramiento del Estado y su declinación, debida a la erosión de su soberanía interna y externa, así como a la emergencia de la sociedad civil, marcan, para De Zan, una nueva época histórica. El modelo de las nuevas democracias no debe ser, entonces, fortalecer al Estado, incapaz ya de articular las diversidades sociales en una totalidad homogénea, sino impulsar una sociedad civil autónoma y sus espacios públicos de constitución de poder político democrático de base. El poder comunicativo que se construye en la sociedad civil provee al Estado el recurso de la legitimación, el "fundamento real que sostiene al poder instituido en el sistema republicano y es la condición de la gobernabilidad democrática". ${ }^{9}$ En consecuencia, De Zan avizoraba que "el futuro de la democracia en el siglo XXI depende más de la vitalidad y la autonomía de la sociedad civil que de los procedimientos formales de la representación política y de las instituciones estatales, o de las organizaciones para-estatales". Sin embargo, se mostraba escéptico sobre la voluntad de auto transformación y democratización de la esfera estatal y para-estatal, por lo que el impulso para alcanzar una mayor calidad institucional "tendrá que venir desde fuera del sistema, o sea, de la sociedad civil". La dialéctica Estadosociedad civil no es más que la representación de la tensión entre la libertad y la institucionalidad, que, para nuestro autor, es el motor del proceso de la historia". ${ }^{10}$

8 Ibidem, pp. 137-41 (cursivas del autor). Con valentía intelectual, infrecuente en pensadores democráticos y progresistas, De Zan no vacilaba en acusar, en escritos y presentaciones académicas, a políticos profesionales y a la clase dirigente en general de nuestro país de ser, en parte, resultado, y, en parte, responsables del fracaso del Estado; de componer una "clase dominante", un conglomerado regresivo de corporaciones que se reparten porciones de poder y compiten por la hegemonía de sus intereses y privilegios. Aunque esbozado en el clima conflictivo de la Argentina de los años 2000 y 2001, este pensamiento mantiene inalterada vigencia casi dos décadas después.

${ }^{9}$ Ibidem, pp. 141-42 y 150.

${ }^{10} \mathrm{Ibidem}$, pp. 161-62. Esta aparente invocación anti institucionalista a la sociedad civil debería ser balanceada con la defensa de De Zan, expresada en el mismo artículo, del "buen funcionamiento de la división republicana de los poderes del Estado", 


\section{Sociedad civil y democracia cosmopolita}

Como ya es admitido por vastas corrientes actuales de pensamiento, la política democrática debe ser pensada también más allá de las fronteras estatales nacionales. Ello supone, además, interpretar la proyección de la sociedad civil al ámbito cosmopolita, el cual, por medio de las redes globales, se libera del encierro en un territorio y toma presencia a través de declaraciones, marchas y reuniones en la escena transnacional. En esta línea de reflexión, De Zan señalaba que, en las múltiples conferencias internacionales sobre problemas globales, así como a través de las reacciones que ellas suscitan en distintos grupos y organizaciones, se van constituyendo los espacios públicos políticos globales, de diálogo y formación de una opinión pública independiente de los Estados nacionales. Son el nuevo poder comunicativo emergente, que, aunque todavía débil, conduce a una "globalización paralela", que rivaliza con la globalización económicofinanciera y los acuerdos políticos cupulares, como los del G20 y de las reuniones Cumbre de Jefes de Estado. ${ }^{11}$

Esta ciudadanía de nuevo tipo requiere de protección transnacional de los derechos, con posibilidad de apelación cuando los mismos sean violados en su propio territorio, lo cual supone la restricción de la soberanía estatal tradicional. Para De Zan, los problemas de la sociedad global no son debidamente atendidos por los Estados, los partidos políticos y las corporaciones internas, a raíz de que todavía la política exterior se rige por los

especialmente, "la imparcialidad e independencia de la Justicia" frente a las coacciones del sistema económico, a los "poderes indirectos" de la sociedad civil y a los poderes políticos del Estado. Ellas son indispensables para la defensa de los derechos individuales y la autonomía de la sociedad civil, así como para "el respaldo institucional de las luchas por una sociedad más solidaria, democrática e igualitaria", ya que las mismas deben ser fundamentadas "mediante los principios constitucionales y los valores fundamentales del Derecho". Por ello afirmaba que "la sociedad civil tendrá que luchar siempre por la independencia del poder judicial frente a las ramas políticas del gobierno", para contrarrestar la tendencia recurrente de éstas "a confiscar para sí el poder que la democracia les confía como administradores de la cosa pública" (pp. 159-60).

11 Ibidem, p. 147. 
llamados "intereses nacionales": "solamente los movimientos de opinión y las acciones de la sociedad civil son capaces de movilizar a los Estados a tomar en serio los problemas globales". Es por ello que, a su entender, la idea de una sociedad civil cosmopolita debe luchar contra dos frentes: por un lado, contra las ideologías nacionalistas, al limitar la soberanía nacional para garantizar la paz y el pluralismo; y, por otro, contra el sistema económico globalizado, en la medida en que se requieren imperiosas regulaciones. $\mathrm{La}$ efectiva prioridad de los derechos humanos sobre la soberanía política de los Estados conduce a la ciudadanía cosmopolita, otorgando a los individuos, y no sólo a los Estados o los entes colectivos, la condición de sujetos morales y de derecho en el mundo: "la preservación del pluralismo no puede llevarnos a olvidar la igualdad de todos los hombres como sujetos de los mismos derechos fundamentales". ${ }^{12}$

Coincidente con Habermas, Ferrara y otros autores, De Zan pensaba que tales derechos fundamentales deben ser protegidos por un "estado de derecho sin fronteras", sin que adopte la forma estatal o de un gobierno mundial. A ello agregaba la necesidad de una sociedad civil cosmopolita como

12 Ibidem, pp. 148-49; del mismo autor, "Un estado de derecho común en el mundo", Diálogo Político, Konrad Adenauer Stiftung, XXI, 3 (2004), p. 31 . Deseo contrastar esta defensa que hace De Zan de la ciudadanía cosmopolita para todas las personas, en el segundo de los artículos citados aquí, con la idea rawlsiana acerca de que son los pueblos, y no los Estados, los agentes morales del Derecho de gentes. De Zan destacaba en el planteo de Rawls que aun cuando los pueblos están encuadrados en el ordenamiento doméstico estatal, sus "facultades jurídico-políticas y morales no deben quedar clausuradas en esos espacios particulares". Sin embargo, el filósofo norteamericano se separaba del cosmopolitismo liberal al que adhería De Zan, ya que consideraba que postular una justicia global para las personas con prioridad sobre toda entidad colectiva, como los pueblos, es creer que todas ellas, no importa su procedencia cultural, deben poseer los mismos derechos reconocidos a los ciudadanos de las democracias constitucionales, y que, por tanto, en el ámbito global, sólo sería aceptable un régimen democrático liberal al estilo occidental. (Cfr. De Zan, Julio, "Un estado de derecho común en el mundo", p. 30; Rawls, John, The Law of Peoples, Cambridge/London, Harvard University Press, 1999, pp. 23-24 y 82-83.) Pienso que De Zan percibía y valoraba en la categoría de "pueblos", antes que el cuestionable potencial cultural homogeneizante de los pueblos rawlsianos, una cierta apertura a la diversidad y al entendimiento con otros pueblos que no suelen tener los Estados. 
"comunidad de intereses frente al sistema de la economía global", tal como ésta se mostraba a principios del siglo XXI. ${ }^{13} \mathrm{~A}$ tales efectos, proponía reconstruir el concepto de Derecho y de sociedad civil, sin remitirlos al poder político estatal, "como un sistema de relaciones horizontales y simétricas de reconocimiento recíproco de las personas en cuanto sujetos de derechos iguales, independientemente de todas las diferencias". No obstante, tal estado de derecho trasnacional, aunque no sería una organización estatal clásica, requeriría, para su efectiva institucionalización, que los Estados, a través de pactos y tratados, acordaran limitar su soberanía. ${ }^{14}$

En su libro La gramática profunda del ethos (2013), De Zan creía encontrar en la concepción kantiana de una "comunidad ética universal" el sustento unificador que el sistema jurídico-político global, por sí solo, no podría proveer. Apelando a la filosofía de la religión del pensador alemán, hacía ver que dicha comunidad es una suerte de fin final de los agrupamientos éticos particulares, la idea regulativa conforme a la cual se constituyen. Los individuos, aun cuando sólo podrían ser seres morales al interior de un ethos, tienen a la unión moral del género humano como fin último. Para De Zan, estamos ante una dimensión del ideal cosmopolita no contractual, ni juridizable, en la que se ha avanzado más que en la confederación de Estados prevista por Kant, a través de las múltiples organizaciones y movimientos de derechos humanos, feminismo, defensa del medio ambiente, entre otros, donde se debaten temáticas de interés común de la humanidad, y que, por tanto, son la muestra de una incipiente sociedad civil cosmopolita. ${ }^{15}$ Más aún, desde su punto de vista, la utopía kantiana es interpretable como un avance de la posibilidad de conformar comunidades "impolíticas", una sociedad civil constituida más allá de las instituciones y categorías jurídicas del Estado de derecho. ${ }^{16}$

13 De Zan, Julio, “Un estado de derecho común en el mundo”, pp. 36-37 y 41-42.

14 Ibidem, pp. 43-44.

15 De Zan, Julio, La gramática profunda del ethos. Una lectura de la ética de Kant, Buenos Aires, Las Cuarenta, 2013, pp. 107-08.

16 Ibidem, p. 134; "La ética como categoría de lo impolítico y el pensamiento cosmopolita”, en D. Michelini, J. De Zan y A. Damiani (eds.), Ética, Política y Discurso. Contribuciones desde América Latina, T. II, Río Cuarto, Ediciones del ICALA, 2015, pp. 192-93. 


\section{Reflexiones finales}

En la línea de Habermas, De Zan pensaba que la ética discursiva y la teoría de la democracia deliberativa son un marco teórico eficaz para pensar un orden político global no centrado en el Estado tradicional, sino en la horizontalidad de los discursos públicos. ${ }^{17}$ Las razones estriban en que la teoría de la democracia deliberativa debe ser entendida, al mismo tiempo, como procedimental y como sustantiva, de modo que el tipo de democracia que en ella se plantea no es sólo instrumental, sino que posee un significado valioso por sí misma. El procedimiento de la deliberación democrática resuelve acerca de las pretensiones de validez del discurso político sobre cuestiones sustantivas de verdad y justicia. La validez de esos contenidos y fines no está dada a priori, ni ellos provienen de una instancia exterior al discurso. Antes bien, la deliberación democrática es el procedimiento para decidir sobre los fines comunes y, a la vez, supone el valor sustantivo de la apertura de los espacios públicos. Es por ello que, recordaba De Zan, la tiranía, no sólo suprime la libertad, sino también, la verdad como pretensión de validez que se justifica mediante el discurso. ${ }^{18}$

Sin embargo, creo apreciar en el pensamiento último de De Zan un deslizamiento hacia la legitimación del orden global por vía de la constitución de una poderosa sociedad civil cosmopolita, con el agregado de una conciencia moral universal, siguiendo los pasos de la comunidad ética del género humano de Kant. A mi parecer, acuerdo con Habermas en que los caminos de la legitimación democrática de la sociedad global sin gobierno mundial no son una simple extensión de la que es aplicable al interior del Estado nacional moderno. ${ }^{19}$ Aun cuando la meta de una comunidad ética universal pueda permanecer como un ideal regulativo, impulsándonos a salir del "estado de naturaleza ético" del que hablaba Kant en su filosofía de la religión, el progreso moral por el cual la humanidad vaya acercándose a la paz

17 De Zan, Julio, "La ética como categoría de lo impolítico y el pensamiento cosmopolita", p. 197.

${ }^{18}$ De Zan, Julio, "Filosofía de la democracia hoy", en D. Michelini, J. De Zan y A. Damiani (eds.), Ética, Política y Discurso, pp. 75-76.

${ }^{19}$ Cfr. Habermas, Jürgen, Postmetaphysical Thinking II, trad. C. Cronin, Cambridge, Polity Press, 2017, p. 205. 
y a la realización efectiva de los derechos humanos debe poder concretarse, no sólo por los esfuerzos de una sociedad civil transnacional, sino, principalmente, por medio de una institucionalidad jurídico-política que limite el poder político global y preserve aquellos derechos.

A pesar de estas observaciones, me parece un digno final de este homenaje recordar ideas póstumas de De Zan sobre el estatuto actual de la noción de soberanía estatal, testimonio de una parte sustancial de su pensamiento. Interpretando el texto habermasiano sobre "La soberanía popular como procedimiento" (1988), afirmaba:

La idea de la soberanía ha sido desustancializada, y en el trono vacante del antiguo soberano, o del cuerpo del pueblo personificado del que nos hemos despedido (des verabschiedeten Volkskörpers), en ese lugar vacío (del que se apropiaron después los modernos dictadores o los líderes carismáticos autoritarios), no tiene que sentarse nadie nunca más, porque ese vacío es la condición de la apertura de los espacios de la libertad de los ciudadanos de una república democrática y 'la expectativa de una auto organización soberana de la sociedad"”. 20

Recibido: 12/2018; aceptado: 03/2019

${ }^{20}$ De Zan, Julio, "Espacios públicos y soberanía popular. Soberanía líquida sin sujeto en la teoría de la democracia deliberativa de Habermas", texto leído en el X Coloquio de Ética del Discurso, Río Cuarto, ICALA, 2015 (cursivas del autor). Cfr. además, Habermas, Jürgen, Facticidad y validez. Sobre el derecho y el Estado democrático de derecho en términos de teoría del discurso, pp. 612-16; De Miguel, Jorge R., "Comentario a J. De Zan, 'Espacios públicos y soberanía popular. Soberanía líquida sin sujeto en la teoría de la democracia deliberativa de Habermas", texto leído en el X Coloquio de Ética del Discurso, Río Cuarto, ICALA, 2015. 